\title{
Promoting Women in Academic Medicine during COVID-19 and Beyond
}

KEY WORDS: COVID-19; gender equity; diversity; virtual lecture.

J Gen Intern Med 36(10):3292-4

DOI: $10.1007 / \mathrm{s} 11606-021-07021-y$

(C) Society of General Internal Medicine 2021

\section{INTRODUCTION}

Despite extensive work to improve gender equity in academic medicine, women lag in terms of promotions and leadership positions (1). This inequity intensified during the COVID-19 pandemic which has disproportionately affected women, particularly those at early-career stages, who have been bearing the load of additional caregiving and homeschooling responsibilities (2-4). National surveys of early career faculty also highlighted the devastating impact of the COVID-19-related travel ban and the resultant cancelations of meetings on their careers (5).

One reason for the lower promotion rates of women is impediments to travel for national and international presentations, which are associated with opportunities for networking and collaborations, critical to academic promotion and success (6). Due to the COVID-19-related travel bans, most grand rounds and visiting professorships are now being conducted virtually which has removed barriers to travel and provides an opportunity to involve more women in visiting professorships.

The Center for Faculty Development at the Massachusetts General Hospital (MGH) designed a program to promote women faculty and postdoctoral fellows during COVID-19 by providing the opportunity to serve as virtual visiting scholar at national or international institutions combined with mentorship, coaching, and peer-to-peer networking. In this report, we describe the design and short-term outcomes of this program.

\section{METHODS}

The Anne Klibanski Visiting Scholar Program was established in July 2020 with the goal to identify women faculty and postdoctoral fellows disproportionately affected by COVID19 , and who would benefit from national or international speaking, mentoring, and networking opportunities. The review committee consisted of senior members from different

Received May 29, 2021

Accepted June 30, 2021

Published online July 21, 2021 departments who were tasked to identify opportunities for a visiting lecture in their field and served as sponsors.

A Visiting Lecture Series was created to support and advance the careers of women faculty at MGH, the US, and abroad. These lectures bring together faculty members from outside institutions and MGH on topics that overlap both research areas with the intent to build relationships and advance science across institutional, national, and international borders.

All scholars participated in two individual coaching sessions with a professional leadership coach and were enrolled in a 6-week small-group leadership coaching program focusing on career development and community building. The coaching program covered topics such as imposter syndrome, identifying sponsors, finding and leveraging opportunities, networking, and development of a national reputation. Scholars were encouraged to continue to meet and network after completion of the program.

Selected scholars completed a survey on the impact of the program and answers were compared using the chi-square test. This study was exempt by our institutional review board.

\section{RESULTS}

From 74 applications, we selected 36 scholars for the program (Table 1). All requests to outside institutions to host our scholars were accepted and scholars gave 32 national and 18 international talks. The experience of the scholars was consistently positive and led to new collaborations. In fact, many institutions wanted to implement a similar program, which led to the creation of the Visiting Lecture Series, for which we invited 8 national and 5 international women speakers who were paired with our scholars for joint lectures.

Since the beginning of the program, more than one-third of scholars have been considered for promotion to Assistant or Associate Professor, two received major institutional leadership positions, one a tenure track position, and five received other awards.

The survey response rate was $94 \%$. There was a significant increase $(p<0.05)$ in the number of scholars who agreed or strongly agreed that by implementing the award, MGH created an environment that promotes a culture of mentorship and visibility, increases knowledge of available institutional 
Table 1 Demographics of the 36 Selected Anne Klibanski Scholars

\begin{tabular}{llll}
\hline \hline Degree $\begin{array}{c}\text { Postdoctoral } \\
\text { fellow }\end{array}$ & Instructor & $\begin{array}{l}\text { Assistant } \\
\text { professor }\end{array}$ & $\begin{array}{l}\text { Associate } \\
\text { professor }\end{array}$ \\
\hline MD & 2 & 17 & 5 \\
PhD & 1 & 4 & 2 \\
MD, & & 2 & \\
PhD & & & \\
Department & & \\
Anesthesia & & \\
Dermatology & & \\
Emergency service & & & \\
Medicine & & \\
Cancer center & & & \\
Neurology & & & \\
Ophthalmology & & & \\
Orthopedics & & \\
Pathology & & \\
Pediatric surgery & & & \\
Psychiatry & & \\
Radiation oncology & & & \\
Radiology & & \\
Surgery & & & \\
\hline
\end{tabular}

information and resources, and proves that $\mathrm{MGH}$ is open to change (Table 2).

\section{DISCUSSION}

Our study showed that the implementation of a virtual visiting scholar program positively influenced women's careers by providing them the chance to build a national/ international reputation to support their promotion. Given the significant institutional financial constraints due to the pandemic, this initiative presented an innovative low-cost way to support women faculty and trainees, researchers, and clinicians, during a challenging time. In times of crisis, the opportunity to connect with other institutions without barriers and advance their careers as well as to form small communities, equipped the women with a network that will keep expanding and a sounding board that will resonate.

Miriam A. Bredella, $M D^{1}$

Cristina R. Ferrone, $M D^{1}$

Bakhos A. Tannous, $P h D^{1}$

Karan A. Patel, MHA ${ }^{1}$

Anne S. Levy, $P h D^{1}$

Mary L. Bouxsein, PhD ${ }^{1}$

${ }^{1}$ Center for Faculty Development, Massachusetts General Hospital,

Boston, MA, USA

Corresponding Author: Miriam A. Bredella, MD; Center for Faculty Development, Massachusetts General Hospital, Boston, MA, USA (e-mail: mbredella@mgh.harvard.edu).

Funding The study was supported in part by NIH grant K24DK109940.

\section{Declarations:}

Conflict of Interest: The authors declare that they do not have a conflict of interest.

Table 2 Program Feedback Survey Administered Prior To and 9 Months After Start of the Program

\begin{tabular}{|c|c|c|c|c|c|c|c|}
\hline & \multicolumn{7}{|c|}{ AK Visiting Scholar Pre-Program Survey } \\
\hline & $\begin{array}{l}\text { Strongly } \\
\text { agree/agree }\end{array}$ & $\begin{array}{l}\text { Neither } \\
\text { disagree nor } \\
\text { agree }\end{array}$ & $\begin{array}{l}\text { Disagree } \\
\text { /strongly dis- } \\
\text { agree }\end{array}$ & $\begin{array}{l}\text { Strongly } \\
\text { agree/agree }\end{array}$ & $\begin{array}{l}\text { Neither } \\
\text { disagree nor } \\
\text { agree }\end{array}$ & $\begin{array}{l}\text { Disagree } \\
\text { /strongly dis- } \\
\text { agree }\end{array}$ & $\begin{array}{l}p \\
\text { value }\end{array}$ \\
\hline $\begin{array}{l}\text { Environment that promotes a } \\
\text { culture of mentorship }\end{array}$ & $51.61 \%$ & $12.90 \%$ & $35.48 \%$ & $75.76 \%$ & $9.09 \%$ & $15.15 \%$ & 0.0459 \\
\hline $\begin{array}{l}\text { Environment that promotes } \\
\text { feedback and sharing of } \\
\text { information }\end{array}$ & $48.39 \%$ & $25.81 \%$ & $25.81 \%$ & $66.67 \%$ & $15.15 \%$ & $18.18 \%$ & 0.142 \\
\hline $\begin{array}{l}\text { Environment that promotes } \\
\text { visibility }\end{array}$ & $38.71 \%$ & $22.58 \%$ & $38.71 \%$ & $63.64 \%$ & $24.24 \%$ & $12.12 \%$ & 0.0478 \\
\hline $\begin{array}{l}\text { Environment that provides } \\
\text { actionable advice and } \\
\text { guidance }\end{array}$ & $45.16 \%$ & $22.58 \%$ & $32.26 \%$ & $60.61 \%$ & $24.24 \%$ & $15.15 \%$ & 0.2194 \\
\hline $\begin{array}{l}\text { Knowledge of available } \\
\text { institutional information }\end{array}$ & $41.94 \%$ & $41.94 \%$ & $16.13 \%$ & $75.76 \%$ & $15.15 \%$ & $9.09 \%$ & 0.0063 \\
\hline $\begin{array}{l}\text { Knowledge of how to access } \\
\text { institutional resources }\end{array}$ & $41.94 \%$ & $38.71 \%$ & $19.35 \%$ & $75.76 \%$ & $12.12 \%$ & $12.12 \%$ & 0.0063 \\
\hline $\begin{array}{l}\text { Someone to turn to in case of } \\
\text { difficulty }\end{array}$ & $67.74 \%$ & $9.68 \%$ & $22.58 \%$ & $84.85 \%$ & $6.06 \%$ & $9.09 \%$ & 0.1091 \\
\hline $\begin{array}{l}\text { Faculty feel they are part of a } \\
\text { close-knit team. }\end{array}$ & $41.94 \%$ & $29.03 \%$ & $29.03 \%$ & $60.61 \%$ & $27.27 \%$ & $12.12 \%$ & 0.1384 \\
\hline Faculty share information. & $45.16 \%$ & $41.94 \%$ & $12.90 \%$ & $66.67 \%$ & $18.18 \%$ & $15.15 \%$ & 0.0854 \\
\hline $\begin{array}{l}\text { Faculty strive to support each } \\
\text { other. }\end{array}$ & $51.61 \%$ & $22.58 \%$ & $25.81 \%$ & $57.58 \%$ & $27.27 \%$ & $15.15 \%$ & 0.6343 \\
\hline $\begin{array}{l}\text { Your work is consistent with } \\
\text { your expectations. }\end{array}$ & $61.29 \%$ & $22.58 \%$ & $16.13 \%$ & $69.70 \%$ & $24.24 \%$ & $6.06 \%$ & 0.4824 \\
\hline $\mathrm{MGH}$ is open to change. & $38.71 \%$ & $35.48 \%$ & $25.81 \%$ & $69.70 \%$ & $12.12 \%$ & $18.18 \%$ & 0.0135 \\
\hline
\end{tabular}




\section{REFERENCES}

1. Richter KP, Clark L, Wick JA, Cruvinel E, Durham D, Shaw P, et al. Women Physicians and Promotion in Academic Medicine. N Engl J Med. 2020;383(22):2148-57.

2. Andersen JP, Nielsen MW, Simone NL, Lewiss RE, Jagsi R. COVID-19 medical papers have fewer women first authors than expected. Elife. 2020 Jun 15;9:e58807.

3. Cardel MI, Dean N, Montoya-Williams D. Preventing a Secondary Epidemic of Lost Early Career Scientists. Effects of COVID-19 Pandemic on Women with Children. Ann Am Thorac Soc. 2020;17(11): 1366-70.

4. Malisch JL, Harris BN, Sherrer SM, Lewis KA, Shepherd SL, McCarthy PC, et al. Opinion: In the wake of COVID-19, academia needs new solutions to ensure gender equity. Proc Natl Acad Sci U S A. 2020;117(27):15378-81.

5. McCormack WT, Bredella MA, Ingbar DH, Jackson RD, Meagher EA, Morris CD, et al. Immediate impact of the COVID-19 pandemic on CTSA
TL1 and KL2 training and career development. J Clin Transl Sci. 2020;4(6):556-61.

6. Sharpe EE, Moeschler SM, O'Brien EK, Oxentenko AS, Hayes SN. Representation of Women Among Invited Speakers for Grand Rounds. J Women's Health (Larchmt). 2020;29(10):1268-72.

Publisher's Note Springer Nature remains neutral with regard to jurisdictional claims in published maps and institutional affiliations. 